Jurnal Keperawatan, Volume 9, No. 1, Februari 2021, (Hal. 9-18)

\title{
HUBUNGAN EXPRESSED EMOTION KELUARGA DAN PEER SUPPORT DENGAN SUICIDE IDEATIONPADA REMAJA DI SMP N 8 MANADO
}

\author{
Apryani Lumban Gaol a, Andi Buana Sari b, Hendro Bidjuni c* \\ ${ }^{a}$ Mahasiswa Program Studi Ilmu Keperawatan, Fakultas Kedokteran \\ Universitas Sam Ratulangi, Indonesia \\ ${ }^{b}$ Program Studi Ilmu Keperawatan, Fakultas Kedokteran \\ Universitas Sam Ratulangi, Indonesia \\ c Program Studi Ilmu Keperawatan, Fakultas Kedokteran \\ Universitas Sam Ratulangi, Indonesia \\ * apryanilumbangaol@gmail.com
}

\begin{abstract}
Background Family expressed emotionand peer support is important in shaping the emotional and mentality af a teenager. The purpose of this study is to find out prove the relationship between family expressed emotion and peer support with suicide ideation in Junior High School 8 Manado. The research method used to prove the hypothesis of this study is a quantitative approach, cross sectional, with the Spearman Rank correlation technique. The sample was taken using non-probability techniques, purposively. The sample size was 83 respondents in Junior High School 8 Manado. The results of the study prove that both hypotheses can be accepted. H1 test shows the level of strength (closeness) between variabels is moderate $(0,369)$, positive direction, and significant ( $\mathrm{p}=0,001<\alpha=0,05)$. H2 test shows the level of strength (closeness) between variabels is moderate $(-0,218)$, negative direction, and significant $(\mathrm{p}=0,048<\alpha=$ 0,05). Conclution : there is a moderate, positive and negative and significant relationship between family expressed emotion (36,9\%),peer support $(-21,8 \%)$ with suicide ideation. Suggestions, for school to improve mental health education services and counseling to address adolencent mental health problem and efforts to tackle of suicide ideation in adolescents.
\end{abstract}

Keywords: Family Expressed Emotion; Peer Support; Suicide Ideation

\begin{abstract}
Abstrak
Ekspresi emosi keluarga dan dukungan teman sebaya merupakan hal yang penting dalam pembentukan emosional dan mentalitas remaja.Tujuan dari penelitian ini yaitu untuk mengetahui dan membuktikan hubungan antara ekspresi emosi keluarga dan dukungan teman sebaya dengan gagasan bunuh diri pada remaja di Smp N 8 Manado. Metode penelitian yang digunakan untuk membuktikan hipotesis penelitian ini adalah pendekatan kuantitatif, cross sectional, dengan teknik korelasi Rank Spearman. Sampel diambil dengan menggunakan teknik non-probabilitas. Jumlah sampel adalah 83 responden yang berada di SMP N 8 Manado. Hasil penelitian membuktikan kedua hipotesis dapat diterima. Uji H1 menunjukkan tingkat kekuatan (kedekatan) antara variabel cukup (0,369), arah positif, dan signifikan $(\mathrm{p}=0,001<\alpha=0,05)$. Uji H2 menunjukkan tingkat kekuatan (kedekatan) antara variabel cukup (-0.218), arah negatif, dan signifikan ( $\mathrm{p}=0,048<\alpha=0,05)$. Kesimpulan: ada hubungan yang moderat, positif dan negatif, serta signifikan antara ekspresi emosi keluarga $(36,9 \%)$, dan dukungan teman sebaya ($21,8 \%$ ) dengan gagasan bunuh diri. Saran, bagi sekolah agar meningkatkan layanan pendidikan kesehatan mental dan bimbingan konseling untuk mengatasi masalah kesehatan mental remaja dan upaya untuk mengatasi gagasan bunuh diri.
\end{abstract}

Kata Kunci : Ekspresi Emosi Keluarga; Dukungan Teman Sebaya; Gagasan Bunuh Diri.

Apriyani, Andi, Hendro, HubunganExpressedEmotionKeluarga... 
Jurnal Keperawatan, Volume 9, No. 1, Februari 2021, (Hal. 9-18)

\section{PENDAHULUAN}

Bunuh diri (suicide) dan perilaku kecenderungan bunuh diri (suicidal behavior) merupakan dua istilah dengan pengertian yang berbeda. Bunuh diri didefenisikan sebagai perilaku yang sengaja diinisiasi dan dilakukan individu dengan mengetahui atau mengharapkan hasil yang fatal atau mematikan atas tindakan tersebut mengakhiri hidup (WHO,2014). Sedangkan istilah perilaku kecenderungan bunuh diri (suicidal behavior) mencakup ide bunuh diri (suicide ideation) yang mengacu pada pemikiran untuk terlibat dalam perilaku yang dimaksudkan untuk mengakhiri hidup individu, rencana bunuh diri (suicide plan) yang mengacu pada perumusan tertentu yang melaluinya individu akan mati, dan usaha percobaan bunuh diri (suicide attempt) yang mengacu pada keterlibatan melukai diri sendiri setidaknya niat untuk mengakhiri hidup (Nock et al, 2014). Tindakan bunuh diri merupakan tindakan membunuh diri sendiri dengan cara meracuni diri sendiri dengan pestisida, melompat dari gedung tinggi, menghirup gas berbahaya, mencampurkan berbagai bahan kimia berbahaya untuk di minum ataupun dihirup ( WHO, 2014).

Bunuh diri merupakan salah satu dampak masalah gangguan kesehatan jiwa yang menjadi sorotan dunia saat ini. Secara global, setiap tahunnya lebih dari 800.000 orang meninggal karena bunuh diri atau 1 kematian setiap 40 detik ( Kemenkes RI,2019). Apabila dirata ratakan jumlah orang tewas dengan bunuh diri di dunia dari tahun 2015 sampai tahun 2019 meningkat 4 orang per tahunnya. Di Indonesia, angka bunuh diri terus naik yaitu dari $4,3 \%$ di tahun 2012 menjadi 5,2\% di tahun 2015. Kemudian pada tahun 2016 sampai tahun 2017 angkanya stabil yaitu 3.7 kematian dari 100 ribu penduduk tiap tahunnya. Dari ratusan juta jumlah penduduk di Indonesia, satu orang meninggal dunia akibat bunuh diri per satu jam (WHO,2019).

Mayoritas rentang usia pelaku bunuh diri mencakup kelompok umur remaja hingga dewasa awal, kelompok umur ini rentan dalam menghadapi masalah pribadi, lingkungan yang berhubungan dengan identitas diri, kemandirian, situasi dan kondisi rumah, lingkungan sosial, serta hak dan kewajiban yang dibebankan oleh orang tua mereka (Kementerian Kesehatan Republik Indonesia,2016). Meningkatnya resiko bunuh diri pada usia remaja disebabkan oleh berbagai predictor pencetus bunuh diri seperti masalah depresi, cemas, stress, bullyng dan harga diri rendah (Sari,2018).

Bunuh diri pada remaja di dunia menempati peringkat kedua tertinggi sebagai penyebab kematian pada kelompok usia 15 hingga 19 tahun (WHO,2018). Sedangkan prevalensi perilaku bunuh diri remaja Indonesia usia 13-17 tahun adalah sebanyak $3.9 \%$ remaja telah mencoba bunuh diri minimal satu kali dalam setahun terakhir, $5.6 \%$ remaja telah membuat rencana terkait cara mereka bunuh diri, dan $5.4 \%$ remaja dianggap serius telah mempertimbangkan dan memiliki ide bunuh diri (WHO SEARO,2017).

Kasus bunuh diri pada remaja terjadi karena berbagai faktor resiko bunuh diri diantaranya faktor psikologis, faktor keluarga, faktor lingkungan sosial (Aulia,2016). Terdapat hubungan lingkungan endogen dan eksogen dengan perilaku pada remaja. Lingkungan endogen yaitu agresifitas, perkembangan psikologis dan fisiologis yang tidak sinkron, peer support, dan harga diri yang rendah. Sedangkan lingkungan eksogen yaitu faktor lingkungan emosi keluarga, transisi sekolah, penyangkalan sosial dan tidak berespon 
(Ball \& Blinder,2018). Terdapat hubungan yang signifikan antara dukungan emosional keluarga dengan perilaku remaja. Kurangnya fungsi keluarga, pengawasan orangtua, penolakan orangtua merupakan prediktor yang paling kuat terhadap masalah perilaku remaja (Ali,2016).

Ide bunuh diri pada remaja dipengaruhi oleh banyak hal termasuk di dalamnya pola asuh orangtua dan fungsi keluarga (Diponegoro \& Malik, (2013). Yang menjadi salah satu fungsi keluarga adalah fungsi afeksi, yaitu keluarga dapat memberikan kasih sayang, rasa aman, perhatian diantara anggota keluarga dan membina pendewasaaan kepribadian anak (Kaakinen at al, 2010). Kemampuan orangtua mengekspresikan emosi dengan baik menjadi rujukan bagi anak dalam mengelola emosinya. Sebagai pencipta iklim emosional dalam keluarga, orang tua harus berusaha menciptakan suasana keluarga yang hangat dan ekspresif sebagai pemenuhan kebutuhan emosional (Kidman,2018).

Ekspresi emosi (EE) merupakan kesatuan dari emosi, sikap dan perilaku yang diekspresikan oleh keluarga dalam lingkungan keluarga. Ekspresi emosi merupakan alat ukur situasi emosi dalam keluarga. Remaja dalam lingkungan keluarga yang memiliki ekspresi emosi tinggi mempunyai resiko depresi lebih besar hingga memiliki ide bunuh diri dibandingkan dengan lingkungan keluarga yang ekspresi emosinya rendah. Ekspresi emosi yang tinggi tersebut berupa sikap yang penuh kritik, amarah, dan kebencian. Ekspresi emosi yang tinggi merupakan refleksi sikap negative berupa peran sebagai stressor yang dapat meningkatkan kerentanan dan kekambuhan pada seseorang (Hertinjung \& Partini, 2010).
Menurut penelitian Zai et al (2012) ada hubungan antara keluarga dan perilaku percobaan bunuh diri. Keluarga diketahui berfungsi sebagai mediasi antara konsep diri dan perilaku bermasalah. Anak remaja yang berasal dari keluarga harmonis memiliki kemungkinan besar akan tumbuh dengan konsep diri positif. Hal tersebut sejalan dengan penelitian Chang et al ( 2013) bahwa ada hubungan konsep diri secara umum, dan kehangatan orang tua dalam memprediksi kepuasan hidup remaja. Menurut penelitian Hertinjung \& Partini (2010), bahwa ekspresi emosi yang tinggi dalam keluarga seringkali mengakibatkan gangguan psikologis pada anak. Anak yang sering mendapatkan kritik dan penolakan verbal dalam keluarga akan rentan mengalami depresi dan beresiko melakukan perilaku agresif hingga memiliki gagasan bunuh diri (Hertinjung \& Partini, 2010).

Selain faktor lingkungan keluarga, penyebab depresi remaja juga dipengaruhi oleh lingkungan sekolah, dan lingkungan teman sebaya (Tarwoto, et al 2012). Hasil penelitian Diane \& Debora (2017) menyatakan bahwa ada hubungan antara penolakan teman sebaya dengan ide bunuh diri remaja. Anak yang ditolak dalam lingkungan pertemanannya akan mengurangi peluang untuk berinteraksi dengan teman sebaya yang positif dan kemudian anak tidak bisa mengembangkan keterampilan sosial yang sesuai (Drabick, 2017). Hasil penelitian yang dilakukan oleh Simarmata dan Karo (2018) dengan jumlah sampel 50 orang, pada taraf signifikan $5 \%$ didapatkan nilai koefisien tabel adalah 0,284. Maka Ha diterima artinya bahwa terdapat pengaruh teman sebaya terhadap ide bunuh diri pada remaja ( Simarmata,2018). Hubungan yang baik diantara teman sebaya akan sangat membantu perkembangan aspek sosial anak secara normal. Tetapi anak pendiam yang ditolak oleh teman sebayanya, akan merasa 
Jurnal Keperawatan, Volume 9, No. 1, Februari 2021, (Hal. 9-18)

kesepian dan beresiko menderita depresi. Dari keadaan depresi ini maka remaja akan rentan melakukan perilaku agresif dan berbahaya bahkan merujuk ke perilaku bunuh diri (Stiver \& Miller, 2018).

\section{METODE PENELITIAN}

Jenis penelitian ini bersifat analitik korelasi yaitu penelitian yang ditujukan untuk menggambarkan dua atau lebih fakta dan juga sifat sifat objek yang sedang diteliti dengan pendekatan cross sectional study, yaitu variabel sebab atau resiko dan akibat yang terjadi pada objek penelitian diukur dan dikumpulkan secara simultan, sesaat atau satu kali saja dalam satu kali waktu (dalam waktu yang bersamaan) dan tidak ada follow up (Setiadi,2013). Dimana terdapat dua variabel yang akan menjadi objek penelitian yaitu variabel independen dan variabel dependen. Variabel independen yaitu variabel bebas yang pertama akan diukur adalah expressed emotion keluarga dan variabel independen yang kedua yaitu variabel peer support. Sedangkan yang menjadi variabel dependen atau variabel terikat yaitu suicide ideation pada remaja di SMP N 8 Manado.

Penelitian dilakukan di sekolah SMP N 8 Manado dengan melibatkan pelajar remaja yang bersekolah di sekolah tersebut. Penelitian berlangsung pada bulan Mei hingga bulan September 2020. Populasi dalam penelitian adalah subjek yang memenuhi kriteria yang telah ditetapkan sebelumnya yaitu banyaknya remaja dengan rentang usia 12 -15 tahun kelas 8 di SMP N 8 Manado berjumlah 485 orang.Jumlah sampel yang dihitung berdasarkan rumus adalah berjumlah 83 orang responden. Instrumen yang digunakan dalam penelitian ini terdiri dari tiga instrumen yaitu kuisioner ekpresi emosi keluarga yang dikembangkan oleh Ryan, dkk (2005) yang telah teruji validitas dan reliabilitas. Instrumen dukungan sosial teman sebaya yang digunakan dalam penelitian ini merupakan hasil adaptasi dan modifikasi dari penelitian Wahyudi (2016) yang dibuat berdasarkan aspek dukungan sosial yang dikembangkan oleh Sarafino (1994) dan telah memenuhi uji validitas dan reliabilitas. Scale of Suicide Ideation sebagai alat ukur tentang ide bunuh diri pada remaja yang diperkenalkan oleh Beck, et al (1979). Instrument tersebut kemudian dimodifikasi dan dikembangkan pada tesis oleh Aulia (2016). Uji validitas dan reliabilitas telah dilakukan untuk menguji instrument. 
Jurnal Keperawatan, Volume 9, No. 1, Februari 2021, (Hal. 9-18)

\section{HASIL}

\subsection{Distribusi Frekuensi Analisis Data Univariat}

\begin{tabular}{|c|c|c|}
\hline Karakteristik Responden & Frekuensi (n) & Persentase (\%) \\
\hline \multicolumn{3}{|l|}{ Usia } \\
\hline 12 tahun & 1 & 1.2 \\
\hline 13 tahun & 22 & 26.5 \\
\hline 14 tahun & 45 & 54.2 \\
\hline 15 tahun & 15 & 18.1 \\
\hline Total & 83 & 100.0 \\
\hline \multicolumn{3}{|l|}{ Kelas } \\
\hline VII & 14 & 16,9 \\
\hline VIII & 38 & 45,8 \\
\hline IX & 31 & 37,3 \\
\hline Total & 83 & 100.0 \\
\hline \multirow{2}{*}{\multicolumn{3}{|c|}{$\begin{array}{ll}\text { Riwayat } & \text { Tinggal } \\
\text { Bersama } & \end{array}$}} \\
\hline & & \\
\hline Orang tua & 78 & 94.0 \\
\hline Kakek/Nenek & 3 & 3.6 \\
\hline Saudara & 2 & 2.4 \\
\hline Total & 83 & 100.0 \\
\hline \multicolumn{3}{|l|}{ Jenis Kelamin } \\
\hline Perempuan & 63 & 75.9 \\
\hline Laki - Laki & 20 & 24.1 \\
\hline Total & 83 & 100.0 \\
\hline \multicolumn{3}{|l|}{ Ekspresi Emosi } \\
\hline Tinggi & 21 & 25.3 \\
\hline Sedang & 61 & 73.5 \\
\hline Rendah & 1 & 1.2 \\
\hline Total & 83 & 100.0 \\
\hline \multicolumn{3}{|l|}{ Peer Support } \\
\hline Tinggi & 10 & 12.0 \\
\hline Sedang & 60 & 72.3 \\
\hline Rendah & 13 & 15.7 \\
\hline Total & 83 & 100.0 \\
\hline \multicolumn{3}{|l|}{ Suicide ideation } \\
\hline Tinggi & 8 & 9.6 \\
\hline Rendah & 75 & 90.4 \\
\hline Total & 83 & 100.0 \\
\hline
\end{tabular}

Sumber : Data Primer, 2020 
Jurnal Keperawatan, Volume 9, No. 1, Februari 2021, (Hal. 9-18)

Tabel diatas menunjukan bahwa responden terbanyak ada pada kategori usia 14 tahun yaitu sebanyak 45 orang $(54,2 \%)$, dan yang terendah ada pada kategori usia 12 tahun sebanyak 1 orang $(1,2 \%)$. Tabel diatas menunjukan bahwa kategori responden terbanyak berada di jenjang kelas VIII yaitu sebanyak 38 orang $(45,8 \%)$, dan kategori responden yang terendah berada di kelas VII sebanyak 14 orang $(16,9 \%)$.

Tabel diatas menunjukan bahwa kategori responden terbanyak tinggal bersama dengan orangtua yaitu sebanyak 78 orang (94.0\%), dan kategori responden yang terendah tinggal bersama dengan saudara yaitu sebanyak 2 orang (2.4\%). Tabel diatas menunjukan bahwa kategori responden terbanyak berjenis kelamin perempuan yaitu sebanyak 63 orang (75.9\%), dan kategori responden yang terendah berjenis kelamin laki -laki yaitu sebanyak 20 orang (24.1\%).
Pada Tabel di atas menunjukan bahwa dari total 83 responden (100\%) terdapat sebanyak 21 orang responden dengan kategori ekspresi emosi keluarga tinggi $(25.3 \%)$, responden yang memiliki ekspresi emosi keluarga sedang sebanyak 61 orang $(73.5 \%)$, dan responden yang memiliki ekspresi emosi keluarga rendah sebanyak 1 orang (1.2\%).

Pada Tabel di atas menunjukan bahwa dari total 83 responden $(100 \%)$ terdapat sebanyak 10 orang (12.0\%), memiliki peer support tinggi dan 62 orang $(72.3 \%)$, memiliki peer support sedang dan 13 orang $(15.7 \%)$ responden dengan peer support rendah. Pada Tabel di atas menunjukan bahwa dari total 83 responden $(100 \%)$ terdapat sebanyak 8 orang $(9.6 \%)$ yang memiliki Suicide ideation tinggi dan 75 orang $(90,4 \%)$ memiliki suicide ideation rendah.

\subsection{Distribusi Frekuensi Analisis Data Univariat}

\subsubsection{Hubungan Ekspresi Emosi Keluarga dengan Suicide Ideation}

Tabel 5.2.1 Analisis Hubungan Ekspresi Emosi Keluarga dengan Suicide Ideation $(\mathrm{N}=83)$

\section{Ekspresi emosi}

Suicide ideation

\begin{tabular}{|c|c|c|c|c|}
\hline \multirow{6}{*}{$\begin{array}{c}\text { Spearman's } \\
\text { rho }\end{array}$} & \multirow{3}{*}{$\begin{array}{c}\text { Ekspresi } \\
\text { emosi }\end{array}$} & $\begin{array}{l}\text { Correlation } \\
\text { Coefficien }\end{array}$ & 1.000 & . 369 \\
\hline & & $\begin{array}{l}\text { Sig. } \\
\text { tailed) }\end{array}$ & & .001 \\
\hline & & $\mathrm{N}$ & 83 & 83 \\
\hline & \multirow{3}{*}{$\begin{array}{l}\text { Suicide } \\
\text { ideation }\end{array}$} & $\begin{array}{l}\text { Correlation } \\
\text { Coefficient }\end{array}$ & .369 & 1.000 \\
\hline & & $\begin{array}{l}\text { Sig. } \\
\text { tailed) }\end{array}$ & .001 & . \\
\hline & & $\mathrm{N}$ & 83 & 83 \\
\hline
\end{tabular}

Sumber : Data Primer, 2020

Apriyani, Andi, Hendro, HubunganExpressedEmotionKeluarga... 
Berdasarkan tabel diatas menunjukan bahwa dari total responden 83 orang (100\%) didapati hasil uji hipotesis yang dilakukan menggunakan uji Spearman Rank menunjukan nilai $\mathrm{p}=0,001<\alpha=0,05$. Dengan demikian dapat disimpulkan bahwa terdapat hubungan yang signifikan antara ekspresi emosi dengan suicide ideation pada remaja, selanjutnya tingkat kekuatan sebesar
0,369 atau hubungan cukup, dan arah hubungan bernilai positif yaitu 0,369 sehingga hubungan kedua variable bersifat searah. Dapat diartikan bahwa semakin tinggi ekspresi emosi dalam keluarga maka semakin tinggi pula suicide ideation pada remaja.

\subsubsection{Hubungan Peer Support Remaja dengan Suicide Ideation}

Tabel 5.2.2 Analisis Hubungan Peer Support dengan Suicide Ideation ( $\mathrm{N}=83)$

\begin{tabular}{|c|c|c|c|c|}
\hline & & & Peer Support & Suicide ideation \\
\hline \multirow{6}{*}{$\begin{array}{c}\text { Spearman's } \\
\text { rho }\end{array}$} & \multirow{3}{*}{$\begin{array}{c}\text { Peer } \\
\text { Support }\end{array}$} & $\begin{array}{l}\text { Correlation } \\
\text { Coefficien }\end{array}$ & 1.000 & -218 \\
\hline & & $\begin{array}{l}\text { Sig. } \\
\text { tailed) }\end{array}$ & & .048 \\
\hline & & $\mathrm{N}$ & 83 & 83 \\
\hline & \multirow{3}{*}{$\begin{array}{c}\text { Suicide } \\
\text { ideation }\end{array}$} & $\begin{array}{l}\text { Correlation } \\
\text { Coefficient }\end{array}$ &.-218 & 1.000 \\
\hline & & $\begin{array}{l}\text { Sig. } \\
\text { tailed) }\end{array}$ & .048 & . \\
\hline & & $\mathrm{N}$ & 83 & 83 \\
\hline
\end{tabular}

Sumber : Data Primer, 2020

Berdasarkan tabel diatas menunjukan bahwa dari total responden 83 orang (100\%) didapati hasil uji hipotesis yang dilakukan menggunakan uji Spearman Rank menunjukan nilai $\mathrm{p}=0,048<\alpha=0,05$. Dapat disimpulkan bahwa terdapat hubungan yang signifikan antarapeer support dengan suicide ideation pada remaja, selanjutnya tingkat kekuatan sebesar -0.218 yang artinya peer support dengan suicide ideation memiliki hubungan cukup kuat dan arah hubungan bernilai negative yaitu -0.218 sehingga hubungan kedua variable bersifat negative atau tidak searah. Dari hubungan ini dapat disimpulkan bahwa jika peer support rendah maka suicide ideation pada remajaakan meningkat.

\section{PEMBAHASAN}

\section{Hubungan Ekspresi Emosi Keluarga} dengan Suicide Ideation

Hasil uji hipotesis yang dilakukan menggunakan uji Spearman Rank dengan tingkat kepercayaan $95 \% \quad(\alpha=0,05)$ menunjukan adanya hubungan yang signifikan antara ekspresi emosi dengan dengan suicide ideation di Smp N 8 Manado dimana nilai $\mathrm{p}=0,001$ lebih kecil dari nilai $\alpha=0,05$. Tingkat kekuatan sebesar 0,369 berarti hubungan cukup, dan arah hubungan bernilai positif yaitu 0,369 sehingga hubungan kedua variable bersifat searah. Dapat diartikan bahwa jika ekspresi emosi semakin tinggi maka suicide ideation juga meningkat. Emosi keluarga yang negative membuat remaja memiliki depresi yang berat dan memungkinkan mahasiswa memiliki ide untuk bunuh diri. Remaja yang gagal atau tidak mampu meraih ekspektasi 
keluarga karena terlalu dipaksa oleh orangtua juga memiliki potensi membuat remaja malu dan akhirnya kehilangan kepercayaan diri, juga tidak lagi mendapatkan dukungan dari keluarga.

Berdasarkan hasil penelitian responden yang berjenis kelamin perempuan lebih banyak yakni 63 orang $(75,9 \%)$ dibanding laki-laki yang hanya berjumlah 20 orang $(24,1 \%)$. Ada perbedaan gender dalam mengontrol dan meng-ekspresikan emosi. Dalam menghadapi suatu masalah, perempuan akan lebih lemah dan menjadi lebih pasif (Romer et al, 2011). Karakteristik usia responden terbanyak ada pada rentang 14 tahun sebanyak 45 orang (54,2\%). Sebaran usia responden paling sedikit berada di usia 12 tahun berjumlah 1 orang $1.2 \%$ ). Hal ini sesuai dengan pernyataan WHO bahwa $75 \%$ gangguan mental emosional terjadi sebelum usia 24 tahun dan $50 \%$ timbul sebelum usia 15 tahun. Usia mempengaruhi cara pandang individu dalam menghadapi masalah (Potter \& Perry, 2005).

Emosi dalam keluarga seperti dasar penentuan remaja dan juga anggota keluarga dalam berekspresi. Dukungan dan emosi keluarga berperan penting dalam meminimalkan pertumbuhan mental remaja dan meningkatkan adaptasi dengan baik. Maka ekspresi emosi keluarga memiliki pengaruh yang signifikan terhadap ide bunuh diri remaja.

\section{Hubungan Peer Support dengan Suicide Ideation}

Hasil uji hipotesis yang dilakukan menggunakan uji Spearman Rank dengan tingkat kepercayaan 95\% $(\alpha=0,05)$ menunjukan adanya hubungan peer support dengan suicide ideation di Smp N 8 Manado dimana nilai $\mathrm{p}=0,048$ lebih kecil dari nilai $\alpha=0,05$. Tingkat kekuatan sebesar -0.218 atau hubungan cukup, dan arah hubungan bernilai negatif yaitu -0.218 sehingga hubungan kedua variable bersifat tidak searah. Variabel tidak searah dapat diartikan bahwa semakin tinggi peer pupport maka suicide ideation akan semakin rendah, dan juga sebaliknya semakin rendah peer support maka suicide ideation semakin tinggi. Maka sesuai dengan hipotesis awal penulis bahwa terdapat hubungan antara peer support dengan suicide ideation pada remaja di Smp N 8 Manado.

Hasil penelitian ini sesuai dengan hasil penelitian Sarafino (2018) dengan uji statistic multivariate ditemukan bahwa variabel yang paling berhubungan dengan ide bunuh diri pada siswa remaja di Kabupaten Pasaman adalah lingkungan teman sebaya dengan nilai OR sebesar 6.089. Nilai OR ini menunjukkan bahwa yang mempunyai lingkungan teman sebaya yang negative akan memiliki peluang 6 kali memiliki masalah mental dan emosional. Teman sebaya akan bisa bersifat positif dan negatif. Teman sebaya yang positif adalah lingkungan teman sebaya yang saling menerima satu sama lain, saling menghargai dan saling melengkapi antar teman.

Menurut Septi \& Tuti (2011), hubungan dengan teman sebaya bisa bersifat positif dan negatif. Teman sebaya yang memberi motivasi dan peluang untuk mengaktualisasikan diri dalam hal positif merupakan kelompok yang bermanfaat untuk perkembangan emotional remaja. Namun penolakan dan pengabaian teman sebaya dan menjerumuskan anggotanya kedalam hal negatif merupakan dampak negative dari teman sebaya bagi remaja.

\section{KESIMPULAN}

Berdasarkan hasil penelitian dan pembahasan yang telah dipaparkan maka ditarik kesimpulan pada penelitian ini adalah sebagai berikut:

1. Terdapat hubungan yang signifikan antara Expressed Emotion Keluarga 
Jurnal Keperawatan, Volume 9, No. 1, Februari 2021, (Hal. 9-18)

dengan Suicide Ideation pada Remaja di Smp N 8 Manado

2. Terdapat hubungan yang signifikan antara Peer Support dengan Suicide Ideation pada Remaja di Smp N 8 Manado

\section{SARAN}

Bagi peneliti selanjutnya diharapkan dapat melakukan penelitian yang berkaitan tentang Family Expressed Emotion dan Peer Support dengan Suicide Ideation pada remaja dengan sampel yang lebih banyak dan dapat menganalisis faktor lain yang berkaitan dengan Family Expressed Emotion yang tinggi dan Peer Support yang rendah dengan Suicide Ideation yang tinggi.

\section{DAFTAR PUSTAKA}

Ali, M. \& A. M. (2016). In New Perspectives on Adolescent Risk Behaviour (pp.90 - 148). https://doi.org/10.1017/cbo9780511571 $\underline{138.005}$

Ali, M. (2016). Psikologi Remaja Perkembangan Peserta Didik. Jakarta: Bumi Aksara

Aulia, N. (2016). Analisis Hubungan Faktor Resiko Bunuh Diri dengan Ide Bunuh Diri pada Remaja di Kota Rengat Kabupaten Indragiri Hulu Tahun 2016. Skripsi Universitas Andalas. http://www.google.com/url. diakses tanggal 26 Februari 2020.

Badan Penelitian dan Pengembangan Kesehatan Kementerian Kesehatan RI. 2013. Riset Kesehatan Dasar. Diunduh dari www.depkes.go.id/resources/downlo ad/general/Hasil\%20Riskesdas202013.p $\underline{\mathrm{d} \mathrm{f}}$
Batubara, J. R. (2010). Adolescent Development ( Perkembangan Remaja). Sari Pediatri, 12 (1), 21 29.

Chang, L., Chang, C. M., \& Stew, S. M. (2013). Life Satisfaction, SelfConcept. And Family Relations in Chinese Adolescents and Children, International Journal of Behavioral Development

.(http://jbd.sagepub.com/), 182.

Chen, D,W, Introduction Emotional Inteligence A Practical Guide, (UK: Icon Books Ltd,2012) Hal.5

Depkes RI. (2019). Riset Kesehatan Dasar 2019. Jakarta : Kementerian Kesehatan RI.

Diane Chen, Deborah A. G. Drabick, and D. E. B. 1Divisional. (2017). A Developmental Perspective on Peer Rejection, Deviant Peer Affliation, and Conduct Problems among Youth Diane.Vol: 25 (5), DOI : 1032 1057.

https://doi.org/10.111/mec.13536.Ap plication

Diponegoro, A. M., \& Malik, A. (2013). Hubungan Pola Asuh Otoritatif, Kontrol Diri, Keterampilan Komunikasi dengan Agresifitas Siswa Kelas X SMS N 4 Yogyakarta. Jurnal Bimbingan dan Konseling "Psikopedagogia: II(02), 264- 342.

Eskin. M. (2015). Nonfatal Suicidal Behavior and Related Features in Young Adults in Muslim Majority Countries. Research Protocol.

Fakultas Kedokteran Indonesia (FKUI). (2013). Buku Ajar Psikiatri UI. Edisi 2. Badan Penerbit FKUI. 
Jurnal Keperawatan, Volume 9, No. 1, Februari 2021, (Hal. 9-18)

Hanim, F., Rauf, A., et al., A Case Study. International Journal of Applied Psychology. 2013, Vol 3(1): 1-6 DOI : 10.5923/J.jap.20130301.01

Hertinjung, S. Wisnu., \& Partini. (2010). Gangguan Perilaku Pada Anak SD Ditinjau dari Ekspres Emosi Ibunya. Jurnal Penelitian Dinamika Sosial Ekonomi, Vol. 6 (1) edisi 2010. Universitas Muhammadiyah Surakarta.

Ibrahim, N., Amit, N., Suen, W.Y (2014). Psychological Faktor as Predictors of Suicidal Ideation among Adolescents in Malaysia. PLos ONE, 9 (10) : e110670.doi:10.137/journal.pone.01 10670.

Kaakinen, JR., Gedaly-Duf., Coehlo, D.., Hanson.S.M.H. (2010). Family Health Care Nursing : Theory. Practice and Reasearch. $4^{\text {th }}$ ed. Philadelphia: F.A. Davis Company.

Kemenkes RI. Laporan hasil riset kesehatan dasar (RISKESDAS) Indonesia 2018.

Jakarta : Badan penelitian dan pengembangan kesehatan dasar

Lita. A. K (2013). Hubungan antara Kesepian dengan Ide Bunuh Diri pada Remaja dengan Orangtua yang Bercerai. Jurnal Psikologi Klinis dan Kesehatan Mental. Vol 2 (03). 